\title{
Can Electrostatic Catalysis of Diels-Alder Reactions be Harnessed with pH-Switchable Charged Functional Groups?
}

\author{
Heather M. Aitken ${ }^{\mathrm{a}}$ and Michelle L Coote ${ }^{\mathrm{a},{ }^{*}}$
}

Quantum-chemical calculations at the M06-2X/6-31+G(d,p) and G3(MP2)CC levels of theory are used to assess the feasibility of harnessing charged functional groups to electrostatically catalyse Diels-Alder reactions and alter their regio selectivity. For reaction the of the polar diene 2-pyrone with substituted cyclopentene, $\mathrm{pH}$ switches of nearly $60 \mathrm{~kJ} \mathrm{~mol}^{-1}$ are observed in the gas-phase. To switch regioselectivity however it is necessary to toggle between negatively and positively charged functional groups. With the 6-membered cyclohexene derivatives, similar pH-switches are observed but this time an opportunity to $\mathrm{pH}$-switch diastereomeric selectivity is also observed due to the assymetry of the transition state. When 2-pyrone was replaced with a non-polar diene, cyclopentadiene, $\mathrm{pH}$ switches were understandably smaller but still substantial (ca. $15 \mathrm{~kJ} \mathrm{~mol}^{-1}$ ). Likewise pH switches are attenuated by solvent but remain substantial (ca. $30 \mathrm{~kJ} \mathrm{~mol}^{-1}$ ) in toluene and synthetically useful (ca. $15 \mathrm{~kJ} \mathrm{~mol}^{-1}$ ) even in moderately low polar solvents such as dichloromethane.

\section{Introduction}

The study of external and localised electric fields to harness electrostatic effects has long been the domain of redox chemistry and enzyme catalysis. ${ }^{1-3}$ However, polar organic reactions are also influenced by electrostatics through their ability to stabilize or destabilize charged-separated resonance contributors (Figure 1a). ${ }^{4}$

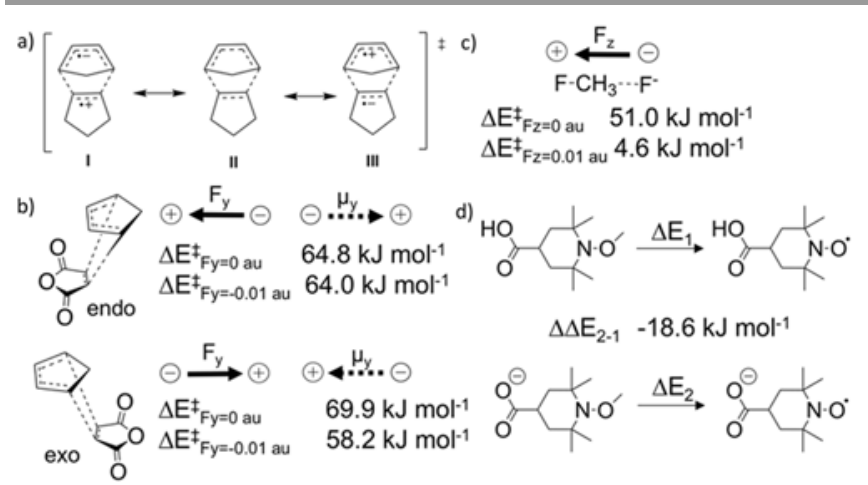

Figure 1 a) Charged-separated resonance contributors ( $\mathbf{l}$ and III) to the transition state of a typical Diels-Alder reaction b) Calculated energy barriers for the reaction between cyclopentadiene and malic anhydride in and without the presence of an electric field (Shaik et.al, 2010) ${ }^{5}$ c) Calculated energy barriers for a halogen transfer reaction in and without the presence of an electric field (Bertran et.al, 1988) ${ }^{6}$ d) Calculated switch in BDE between charged and neutral 4-carboxy-TEMPO species (Coote et.al, 2013) ${ }^{9}$

This was predicted almost a decade ago by Shaik and coworkers for Diels-Alder chemistry (Figure $1 \mathrm{~b}$ ), ${ }^{5}$ and even earlier for simple halogen and hydrogen transfer reactions by Bertran and coworkers ${ }^{6,7}$ (Figure 1c). However, realizing this experimentally poses significant hurdles, due to the directional dependence of the effect. The electric field must be aligned such that it attenuates or strengthens the dipole along the reaction axis ${ }^{5}$. In their Diels-Alder study, Shaik and co-workers further suggested that the electric field could be aligned along the dipole of the diene fragment to influence the regiochemistry of the reaction ${ }^{5}$.

In 2016, these theoretical predictions were finally realized experimentally using scanning tunnelling microscopy (STM) blinking experiments. ${ }^{8}$ The diene and dieneophile were tethered to the tip and plate of the STM respectively, thereby constraining their orientation, while providing a means of both controlling the electric field stimulus and measuring its effect on the single molecule reaction rate. Experiments showed that over the range of field strengths tested the reaction rate was independent of field for positive bias but was catalysed by increasing field strength for negative bias. Parallel quantum-chemical calculations of the same system under the experimental conditions confirmed that these results were due to the effect of the field on the reaction barriers.

Surface chemistry is a low yielding, expensive process, and as such electrostatic catalysis has continued to remain out of reach in conventional organic synthesis. However, we have recently provided computational and experimental proof of concept that electrostatic effects can be provided by charged functional groups in nitroxide chemistry (Figure $1 \mathrm{~d}$ ). ${ }^{9-13}$ By using a charged functional group, a local electric field is generated, with its orientation relative to the reaction centre determined by its location. An additional benefit of this approach is that these functional groups are $\mathrm{pH}$ switchable; that is, the charge and hence field can be turned on or off at will with simple $\mathrm{pH}$ changes.

In implementing the work experimentally in solution, the challenge is to balance the need for a low polarity solvent (so as to maximise field) with the limited solubility of charged species under such conditions. Nonetheless we have shown experimentally 
that such compromises are possible and that sizeable $\mathrm{pH}$ switches are achievable under practical conditions ${ }^{11,13}$ Given this success, the question arises whether or not this approach can be used more broadly. In particular, could charged groups provide a low-tech way to mimic electrostatic catalysis of Diels-Alder reactions? Furthermore, we wondered whether we could design a system that placed a $\mathrm{pH}$-switchable charged functional group in a position that influenced both the regio- and stereoselectivity. In the present work, we use computational chemistry calculations to assess the magnitude of $\mathrm{pH}$ switches and their sensitivity to reaction conditions. Ideally such charged groups would be included on a catalyst, as including them on the substrate would limit the range of applications. However, as a first proof-of-concept study we have included them directly on the substrates.

\section{Computational Methodology}

All calculations in this study were carried out using Gaussian $09^{14}$ and Q-Chem $4.4^{15}$. Geometries were optimized in the gas phase, at the M06-2X/6-31+G(d,p) level of theory, followed by frequency calculations at the same level to confirm the nature of the calculated stationary points. All activation energies were benchmarked against the high level composite method G3(MP2)CC, using M06-2X/6-31+G(d,p) geometries, and found to be within chemical accuracy $\left(5.2 \mathrm{~kJ} \mathrm{~mol}^{-1}\right)$. M06-2X has also been benchmarked in our past studies of $\mathrm{pH}$-switching and shown to provide highly accurate measures of the effect of electric field on a range of chemical processes. ${ }^{8-10}$ All calculations are reported as Gibbs free energies $(G)$ at the $M 06-2 X / 6-31+G(d, p)$ level of theory. Standard textbook formulae, based on the statistical thermodynamics of an ideal gas under the harmonic oscillator and rigid-rotor approximation, were used to determine the thermal and entropic corrections at $298.15 \mathrm{~K}$ and hence the gas-phase Gibbs Free Energies (G). Free energies of solvation $\left(\Delta G_{\text {solv }}\right)$ were calculated using the $S M D / M 06-2 X / 6-31+G(d, p)$ method in toluene, tetrahydrofuran, dichloromethane, pyridine, acetonitrile and water. Using the thermocycle approach, free energies in solution were determined as the sum of the gas phase free energies with the corresponding free energies of solvation and the phase change correction term. ${ }^{16}$

For further computational details, please see the ESI, where we provide all kinetic and thermodynamic parameters and their associated total energies, entropies, solvation energies and geometries. We also provide distortion-interaction analyses of the reactions, and relevant orbital energies and associated analyses of normal and inverse electron demand.

\section{Results and Discussion}

Polar Diene. We began our study by considering the reaction of 2-pyrone (1) with substituted cyclopentenes (Figure 2). Diels Alder reactions with 2-pyrones as the diene have rarely been realised without the use of a catalyst. ${ }^{17}$ As such, we wondered whether we could catalyse the reaction in situ using charged functional groups. We expected the charged group to interact with the large dipole moment of 2-pyrone (4.9D), which points toward the ketone moiety. Carboxylic acid and dimethyl amine groups were chosen as our functional groups, which can switch with $\mathrm{pH}$ to their corresponding conjugate base or acid respectively to provide a charge, and thus a localized electric field. For each reaction studied, the $\mathrm{pH}$-switchable functional group was placed at the 3-position of the dienophile. This places the functional group greater than $3 \AA$ from the reaction centre and without conjugative or hyperconjugative interaction with the reaction centre. As a result, the primary substituent effect can be assumed to be electrostatic, albeit with minor sigma inductive contributions. ${ }^{9}$ Four pathways were considered for each reaction: the exo and endo pathways with the functional group pointing towards (sterically hindered) or away (sterically favoured) from the approaching diene. Enantiomers were not considered.

Both neutral pathways preferred the sterically favoured exo pathway (3c(i), 3c(iii)), presumably due to strong secondary orbital interactions between the dienophile and the ester moiety of the diene. On the other hand, the charged species preferred the sterically hindered pathway to maximise electrostatic stabilisation, and align the localised electric field along the dipole moment of the diene fragment. While the reaction with a protonated amine functional group (positively charged) continued to prefer the exo pathway $(\mathbf{3 c}(\mathbf{i v}))$, reaction with a carboxylate group was calculated to have endo selectivity (3c(iii)).

Furthermore, both charged reactions lowered the activation barrier in the gas phase by approximately $50 \mathrm{~kJ} \mathrm{~mol}^{-1}$ when compared to the corresponding neutral reaction (Figure 2a). This can be explained simply by considering the attenuating effect of the electric field when it opposes the dipole of the approaching diene. By attenuating the dipole of the diene fragment, electrons are no longer pulled away from the reaction centre. This effect is maximised by the endo pathway in the presence of a negatively charged functional group and by the exo pathway in the presence of a positively charged functional group (Figure $2 b$ \& c).

Additionally, the pi and $\mathrm{pi}^{*}$ molecular orbital energies of the distorted diene and dienophile fragments of each transition state, calculated via M062X/6-31+G(d,p) and backed by NBO analysis, were found to differ by less than $0.2 \mathrm{eV}$ between each conformer further supporting the assumption that the switch in reactivity is caused by electrostatic interactions within the transition state. Curiously, the remote charged functional group was calculated to affect the electron demand of the reaction. While the neutral 
reactions were calculated to have competing electron demand, a carboxylate functional group raises the pi and pi* orbitals of the dienophile by ca. $4 \mathrm{eV}$ to promote normal

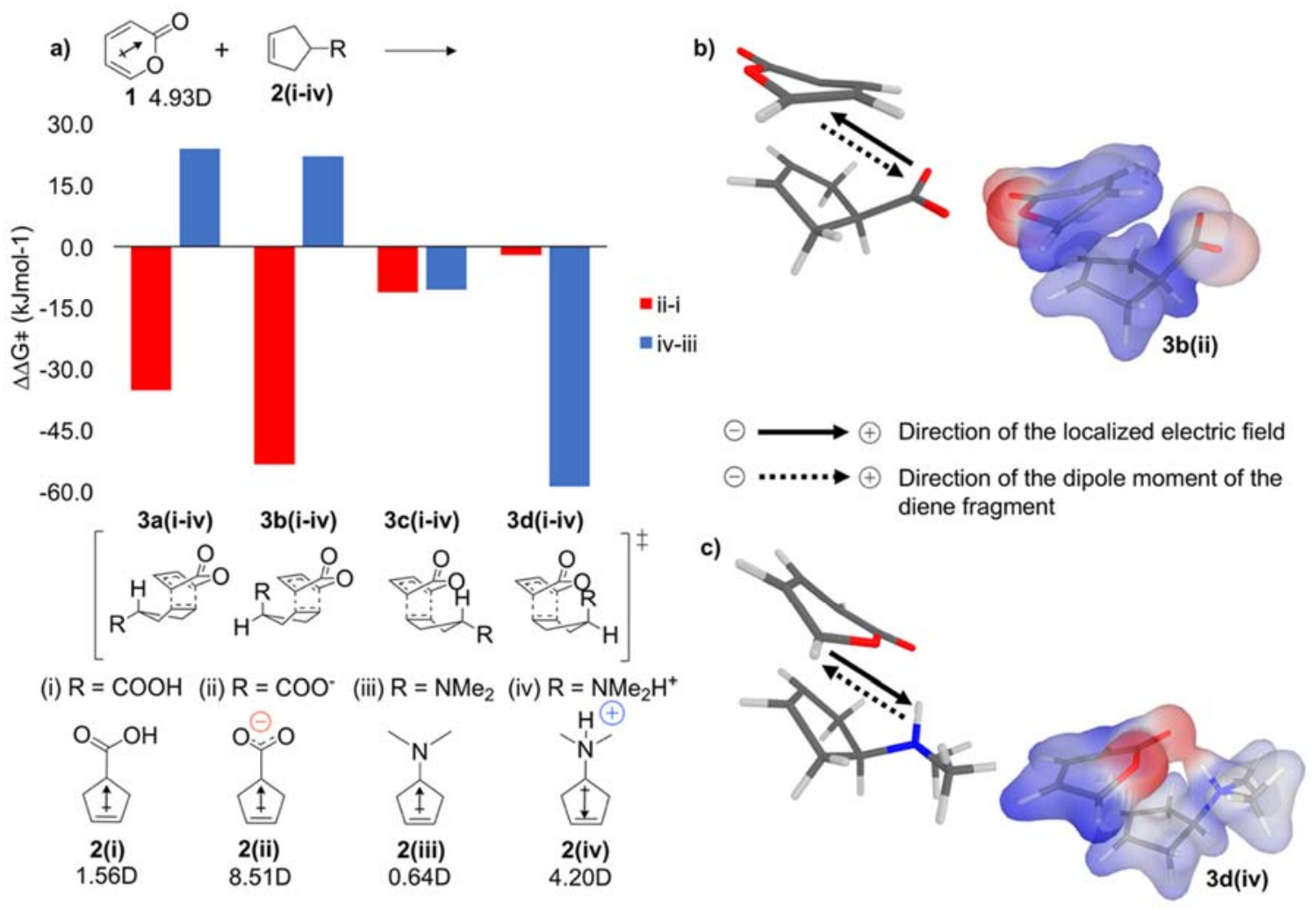

Figure 2 a) Difference in $\Delta G \neq$ between the reaction of 2-pyrone with neutral and deprotonated 3-cyclopentenecarboxylic acid (red) and the reaction of 2-pyrone with neutral and protonated $N, N$-dimethylcyclopent-3-en-1-amine (blue). A negative $\triangle \Delta G \ddagger$ corresponds to a lower activation barrier when charged. b) Calculated lowest energy transition state structure when $\mathrm{R}=\mathrm{COO}(\mathbf{3 b}$ (ii)). The activation barrier is lowered when the localised electric field is parallel and opposing the dipole moment of the 2-pyrone fragment, and the electrostatic potential is stabilised. c) Lowest energy transition state when $\mathrm{R}=\mathrm{NMeH}(\mathbf{3 d}($ iv)). The activation barrier is lowered when
the localised electric field is parallel and opposing the dipole moment of the 2-pyrone fragment, and the electrostatic potential is stabilised.

electron demand reactivity. On the other hand, the protonated dimethyl amine functional group lowers the pi and pi* orbitals of the dienophile by ca. $4 \mathrm{eV}$ to promote inverse electron demand reactivity (Figure S1, Electronic Supporting Information).

Effect of Dienophile Ring Size. Given the clear sensitivity of these reactions to the position of the charged functional group, we chose to consider the effect of increasing the size of the dienophile to cyclohexene. This created an additional level of asymmetry - the $\mathrm{pH}$-switchable functional group on the dienophile could be on either the same or the opposite side of the ketone moiety on the diene - doubling the number of possible transition states to 8 (Figure 3a).

As expected, all reactions were calculated to have similar sensitivity to electrostatic effects, as observed for the corresponding cyclopentene reactions. Thus, they were likewise catalysed by ca. $50 \mathrm{~kJ} \mathrm{~mol}^{-1}$ once charged. Furthermore, the charged reactions consistently favoured the transition state geometry $(\mathbf{5 b}(\mathbf{i i )} \mathbf{\&} \mathbf{5 g}(\mathbf{i v}))$ which placed the charged functional group on the opposite side of the ketone moiety of the diene. The difference in $\Delta \mathrm{G}^{\ddagger}$ between $\mathbf{5 c}$ (ii) and $\mathbf{5 d}$ (ii), and between $\mathbf{5 g}$ (iv) and $\mathbf{5 h}$ (ii) was ca. $5 \mathrm{~kJ}$ $\mathrm{mol}^{-1}$ or approximately an order of magnitude in the rate constant. Once again, we can suggest an explanation for this calculated result by considering the ability of the localised electric field to attenuate the dipole moment of the diene. As shown previously ${ }^{10}$, electrostatic effects are highly directional; by considering our transition state geometries we observe that when the localised electric field aligns itself parallel to the dipole moment of the diene the stabilising effect is stronger, thus providing exclusive diastereomeric selectivity (Figure $3 b$ \& c).

Non-Polar Diene. With such a large decrease in the activation barrier using a polar diene we considered the possibility of $\mathrm{pH}$ switchable Diels-Alder reactions using the relatively non-polar cyclopentadiene (0.9D) with dieneophiles 2(i-iv) and $\mathbf{4}$ (i-iv) (Figures 4 \& 5). Furthermore, the direction of the dipole moment for the two dienes, albeit very small for cyclopentadiene, are opposing and as such we expected a reversal in the selectivity exhibited by the charged reactions. Again, 4 pathways were considered for each reaction. 
Again, electrostatic stabilisation struggled to compete with the endo-selective stabilising effect of secondary orbital interactions. The neutral reactions were calculated to favour the least sterically hindered endo pathway as were the reactions with the protonated dimethyl amine functional group. Reaction with the carboxylate substituted cyclopentene was also endo selective, albeit for the sterically hindered transition state. On the other hand, the reaction with carboxylate substituted cyclohexene was calculated to proceed through the expected sterically hindered exo transition state, presumably due to increased ring strain hindering secondary orbital interactions. It is interesting to note that the expected trend

a)<smiles></smiles>
14.930<smiles>[R]C1CC=CCC1</smiles>
${ }_{4(\mathrm{i}-\mathrm{i})} \mathrm{R}$

30.0

15.0

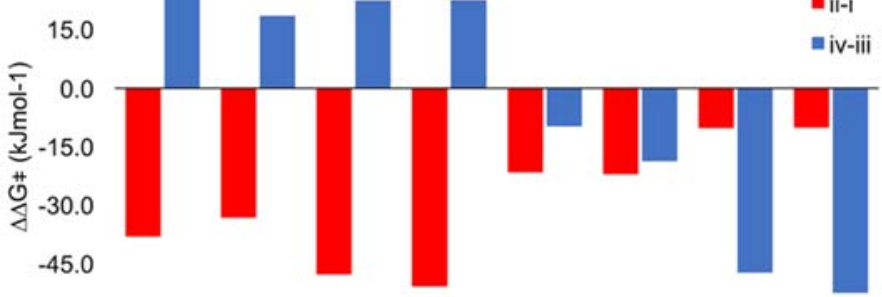

$-60.0$

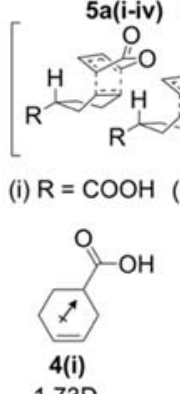

$5 a(i-i v) 5 b(i-i v) 5 c(i-i v) 5 d($ i-iv) 5 e(i-iv) $5 f($ i-iv) $5 \mathrm{~g}$ (i-iv) $5 \mathrm{~h}(\mathrm{i}-\mathrm{iv})$

$1.73 \mathrm{D}$

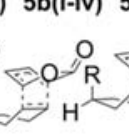

$=\mathrm{O}^{\prime} \mathrm{R}$

$=\mathrm{COO}$

(iii) $R$

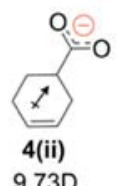

(iii) $\mathrm{R}=\mathrm{NMe}_{2}$

(iv) $\mathrm{R}=\mathrm{NMe}_{2} \mathrm{H}^{+}$
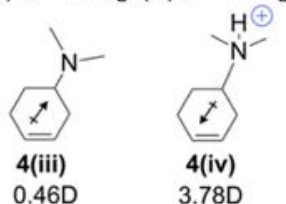

b)

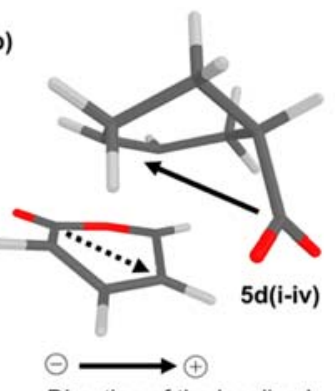

Direction of the localized electric field

$\ominus \cdots \cdots . . \rightarrow \oplus$

Direction of the dipole moment of the diene fragment

c)

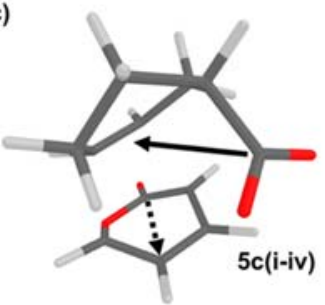

Figure 3 a) Difference in $\Delta G \ddagger$ between the reaction of 2-pyrone with neutral and deprotonated 3-cyclohexenecarboxylic acid (red) and the reaction of 2-pryone with neutral and protonated $N, N$-dimethylcyclohex-3-en-1-amine (blue). A negative $\Delta \Delta G \neq$ corresponds to a lower activation barrier when charged. b) Calculated lowest energy transition state structure when $\mathrm{R}=\mathrm{COO}$ (5d(ii)). The activation barrier is lowered when the localised electric field is parallel and opposing the dipole moment of the 2-pyrone fragment, and the electrostatic potential is stabilised c) For the corresponding transition state of diastereomer (3d(iv)) the localised electric field is oblique to the dipole moment of the 2 -pyrone fragment and is thus less stable relative to $\mathbf{5 d ( i i )}$

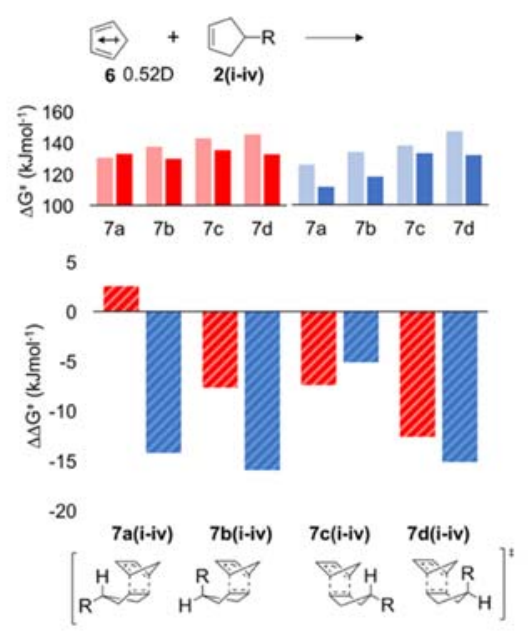

(i) $\mathrm{R}=\mathrm{COOH}$ (ii) $\mathrm{R}=\mathrm{COO}$ (iii) $\mathrm{R}=\mathrm{NMe}_{2}$ (iv) $\mathrm{R}=\mathrm{NMe}_{2} \mathrm{H}^{*}$

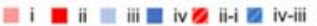

Figure 4 Difference in $\Delta G \ddagger$ between the reaction of cyclopentadiene with neutral and deprotonated 3-cyclopentenecarboxylic acid (red) and the reaction of cyclopentadiene with neutral and protonated N,N-dimethylcyclopent-3-en-1-amine (blue). A negative $\Delta \Delta \mathrm{G} \neq$ corresponds to a lower activation barrier when charged. 


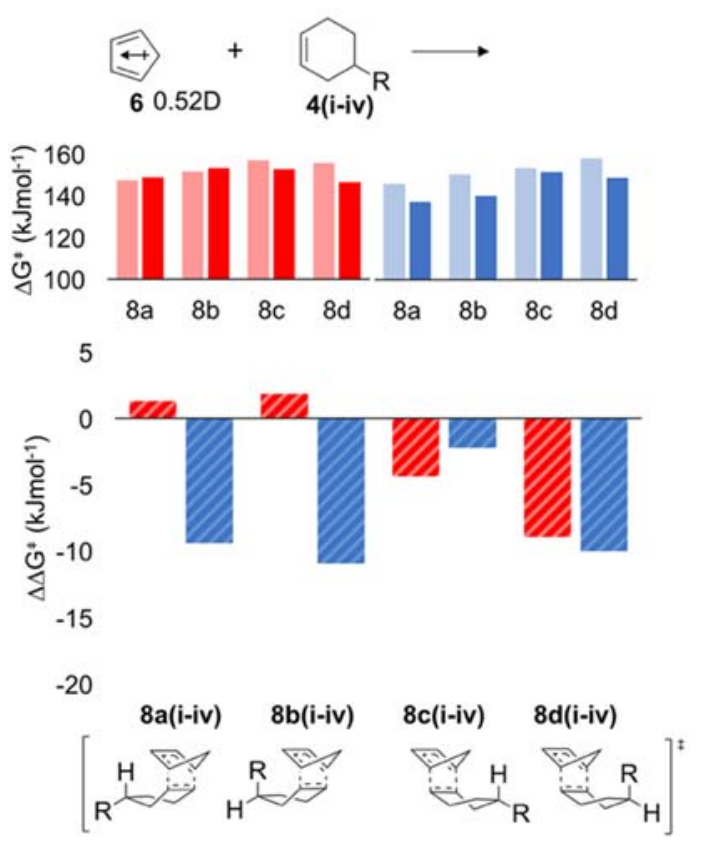

(i) $\mathrm{R}=\mathrm{COOH}$ (ii) $\mathrm{R}=\mathrm{COO}^{-}$(iii) $\mathrm{R}=\mathrm{NMe}_{2}$ (iv) $\mathrm{R}=\mathrm{NMe}_{2} \mathrm{H}^{+}$

i

Figure 5 Difference in $\Delta G \ddagger$ between the reaction of cylcopentadiene with neutral and deprotonated 3-cyclohexenecarboxylic acid (red) and the reaction of cylcopentadiene with neutral and protonated N,N-dimethylcyclohex-3-en-1-amine (blue). A negative $\Delta \Delta \mathrm{G} \neq$ corresponds to a lower activation barrier when charged.

was observed in the magnitude of the $\mathrm{pH}$-switch $\left(\Delta \Delta \mathrm{G}^{\ddagger}\right)$, suggesting that electrostatic effects still influence the stability of transition states in relatively non-polar reactions.

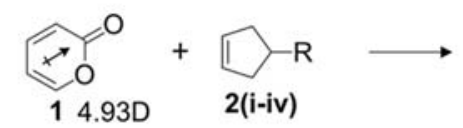

15

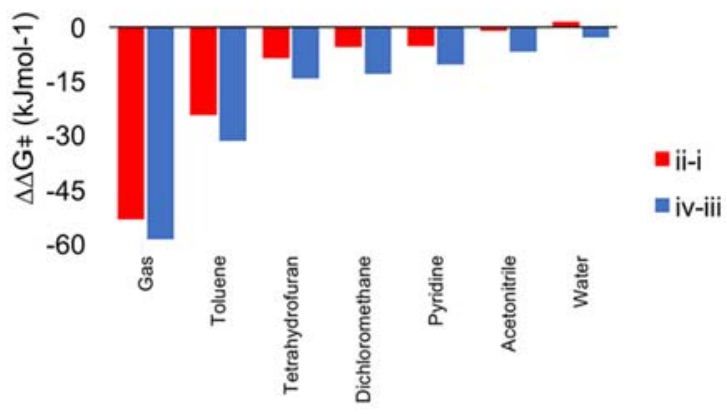

(i) $\mathrm{R}=\mathrm{COOH}$ (ii) $\mathrm{R}=\mathrm{COO}^{-}$(iii) $\mathrm{R}=\mathrm{NMe}_{2}$ (iv) $\mathrm{R}=\mathrm{NMe}_{2} \mathrm{H}^{+}$

Figure 6 Solvent dependence of the $\mathrm{pH}$-switch $(\Delta \Delta \mathrm{G} \ddagger)$ calculated for the largest switch between the reaction of 2-pyrone with neutral (3b(i)) and deprotonated (3b(ii)) 3 -cyclopentenecarboxylic acid (red) and the reaction of 2-pryone with neutral (3c(iii)) and protonated (3c(iv)) N,N-dimethylcyclopent-3-en-1-amine (blue). A negative

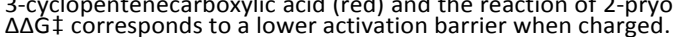

Solvent Effects. We have previously reported that these electrostatic effects are quenched in high polarity solutions where charged species are most commonly soluble. However, compromises between polarity and solubility have been found experimentally, using for example dichloromethane as the solvent to demonstrate sizeable $\mathrm{pH}$-switches on nitroxide radical stability in solutions where all species were soluble. ${ }^{11}$ In the present systems, we see similar trends (Figure 6). The magnitude of the pH-switch is calculated to decrease steadily as the polarity of the solvent increases, yet still remains synthetically useful in toluene, 
tetrahydrofuran, dichloromethane and pyridine; though it is largely lost in acetonitrile and water (Figure 6). Importantly, the magnitude of the $\mathrm{pH}$ switches in solvents such as dichloromethane remain sizeable at up to $13 \mathrm{~kJ} \mathrm{~mol}^{-1}$.

\section{Conclusions}

We predict that it is possible to use remote $\mathrm{pH}$-switchable charged functional groups to switch the regio- and diastereoselectivity of Diels Alder reactions. As expected the largest switch was observed in polar reactions however they are still significant using a non-polar diene. While $\mathrm{pH}$ switches are quenched in polar solvent they are expected to remain significant in non-polar and moderately polar solvents. Even though these functional groups were placed remote to the reaction centre, analysis of the molecular orbitals suggests that they may still affect the electron demand of the reaction. Overall, this provides a useful proof of concept that electrostatic catalysis may be harnessed using $\mathrm{pH}$-switchable functional groups with a view towards $\mathrm{pH}$-switchable catalyst design. More generally this adds to the growing number of external stimuli, such as light ${ }^{18,19}$ and pressure, ${ }^{20}$ that can be harnessed to manipulate this important chemical process.

\section{Conflicts of interest}

There are no conflicts to declare.

\section{Acknowledgements}

M.L.C gratefully acknowledges an ARC Laureate Fellowship and generous allocations on the National Facility of the Australian National Computational Infrastructure.

\section{Notes and References}

1 Warshel, A. Electrostatic basis of structure-function correlation in proteins. Acc. Chem. Res.14, 284-290 (1981).

2 Franzen, S., Goldstein, R. F. \& Boxer, S. G. Electric field modulation of electron transfer reaction rates in isotropic systems: long distance charge recombination in photosynthetic reaction centers. J. Phys. Chem. 94, 5135-5149 (1990).

3 Shaik, S., de Visser, S. P. \& Kumar, D., (2004), External electric field will control the selectivity of enzymatic-like bond activations. J. Am. Chem. Soc. 126, 11746-11749.

4 Shaik, S., Mandal, D., Ramanan, R., (2016), Oriented electric fields as future smart reagents in chemistry. Nature Chemistry, 8: 1091-1098.

5 Meir, R., Chen, H., Lai, W. and Shaik, S. (2010), Oriented Electric Fields Accelerate Diels-Alder Reactions and Control the endo/exo Selectivity. ChemPhysChem, 11: 301-310.

6 J.L. Andrés, A. Lledós, M. Duran, J. Bertrán, (1988), Electric fields acting as catalysts in chemical reactions. An ab initio study of the walden inversion reaction, Chemical Physics Letters, 153, 1, 82-86.

7 Carbonell, E., Duran, M., Lledos, A. \& Bertran, (1991), Catalysis of Friedel-Crafts reactions by electric fields. J. Phys. Chem. 95, 179-183.

8 Aragonés, C., Haworth, N., Darwish, N., Ciampi, S., Bloomfield, N. J., Wallace, G. G., Diez-Perez, I., Coote, M. L., Electrostatic catalysis of a Diels-Alder reaction. Nature 531, 88-91 (2016).

9 Gryn'ova G., Marshall D.L., Blanksby S.J. and Coote M.L. Switching Radical Stability By pH-Induced Orbital Conversion Nature Chem. (2013), 5, 474-481.

10 Gryn'ova G., Coote M.L. Origin and scope of long-range stabilizing interactions and associated SOMO-HOMO conversion in distonic radical anions J. Am. Chem. Soc. (2013), 135, 15392-15403. 
11 Klinska, M.; Smith, L. M.; Gryn'ova, G.; Banwell, M. G.; Coote, M. L., Experimental Demonstration of pH-Dependent Electrostatic Catalysis of Radical Reactions Chem. Sci., (2015) 6, 5623-5627.

12 Gryn'ova, G.; Coote, M.L., Directionality and the Role of Polarization in Electric Field Effects on Radical Stability Aust. J. Chem., (2017) 70, 367-372.

13 Gryn'ova, G.; Smith, L.M.; Coote, M.L., Computational Design of pH-Switchable Control Agents for Nitroxide mediated Polymerization Phys. Chem. Chem. Phys., (2017) 19, 22678-22683.

14 Gaussian 09, Revision E.01, M. J. Frisch, G. W. Trucks, H. B. Schlegel, G. E. Scuseria, M. A. Robb, J. R. Cheeseman, G. Scalmani, V. Barone, G. A. Petersson, H. Nakatsuji, X. Li, M. Caricato, A. Marenich, J. Bloino, B. G. Janesko, R. Gomperts, B. Mennucci, H. P. Hratchian, J. V. Ortiz, A. F. Izmaylov, J. L. Sonnenberg, D. Williams-Young, F. Ding, F. Lipparini, F. Egidi, J. Goings, B. Peng, A. Petrone, T. Henderson, D. Ranasinghe, V. G. Zakrzewski, J. Gao, N. Rega, G. Zheng, W. Liang, M. Hada, M. Ehara, K. Toyota, R. Fukuda, J. Hasegawa, M. Ishida, T. Nakajima, Y. Honda, O. Kitao, H. Nakai, T. Vreven, K. Throssell, J. A. Montgomery, Jr., J. E. Peralta, F. Ogliaro, M. Bearpark, J. J. Heyd, E. Brothers, K. N. Kudin, V. N. Staroverov, T. Keith, R. Kobayashi, J. Normand, K. Raghavachari, A. Rendell, J. C. Burant, S. S. Iyengar, J. Tomasi, M. Cossi, J. M. Millam, M. Klene, C. Adamo, R. Cammi, J. W. Ochterski, R. L. Martin, K. Morokuma, O. Farkas, J. B. Foresman, and D. J. Fox, Gaussian, Inc., Wallingford CT, 2016.

15 Y. Shao, Z. Gan, E. Epifanovsky, A. T. B. Gilbert, M. Wormit, J. Kussmann, A. W. Lange, A. Behn, J. Deng, X. Feng, D. Ghosh, M. Goldey P. R. Horn, L. D. Jacobson, I. Kaliman, R. Z. Khaliullin, T. Kús, A. Landau, J. Liu, E. I. Proynov, Y. M. Rhee, R. M. Richard, M. A. Rohrdanz, R. P. Steele, E. J. Sundstrom, H. L. Woodcock III, P. M. Zimmerman, D. Zuev, B. Albrecht, E. Alguire, B. Austin, G. J. O. Beran, Y. A. Bernard, E. Berquist, K. Brandhorst, K. B. Bravaya, S. T. Brown, D. Casanova, C.-M. Chang, Y. Chen, S. H. Chien, K. D. Closser, D. L. Crittenden, M. Diedenhofen, R. A. DiStasio Jr., H. Dop, A. D. Dutoi, R. G. Edgar, S. Fatehi, L. Fusti-Molnar, A. Ghysels, A. Golubeva-Zadorozhnaya, J. Gomes, M. W. D. Hanson-Heine, P. H. P. Harbach, A. W. Hauser, E. G. Hohenstein, Z. C. Holden, T.-C. Jagau, H. Ji, B. Kaduk, K. Khistyaev, J. Kim, J. Kim, R. A. King, P. Klunzinger, D. Kosenkov, T. Kowalczyk, C. M. Krauter, K. U. Lao, A. Laurent, K. V. Lawler, S. V. Levchenko, C. Y. Lin, F. Liu, E. Livshits, R. C. Lochan, A. Luenser, P. Manohar, S. F. Manzer, S.-P. Mao, N. Mardirossian, A. V. Marenich, S. A. Maurer, N. J. Mayhall, C. M. Oana, R. Olivares-Amaya, D. P. O'Neill, J. A. Parkhill, T. M. Perrine, R. Peverati, P. A. Pieniazek, A. Prociuk, D. R. Rehn, E. Rosta, N. J. Russ, N. Sergueev, S. M. Sharada, S. Sharmaa, D. W. Small, A. Sodt, T. Stein, D. Stück, Y.-C. Su, A. J. W. Thom, T. Tsuchimochi, L. Vogt, O. Vydrov, T. Wang, M. A. Watson, J. Wenzel, A. White, C. F. Williams, V. Vanovschi, S. Yeganeh, S. R. Yost, Z.-Q. You, I. Y. Zhang, X. Zhang, Y. Zhou, B. R. Brooks, G. K. L. Chan, D. M. Chipman, C. J. Cramer, W. A. Goddard III, M. S. Gordon, W. J. Hehre, A. Klamt, H. F. Schaefer III, M. W. Schmidt, C. D. Sherrill, D. G. Truhlar, A. Warshel, X. Xua, A. Aspuru-Guzik, R. Baer, A. T. Bell, N. A. Besley, J.-D. Chai, A. Dreuw, B. D. Dunietz, T. R. Furlani, S. R. Gwaltney, C.-P. Hsu, Y. Jung, J. Kong, D. S. Lambrecht, W. Liang, C. Ochsenfeld, V. A. Rassolov, L. V. Slipchenko, J. E. Subotnik, T. Van Voorhis, J. M. Herbert, A. I. Krylov, P. M. W. Gill, and M. Head-Gordon. Advances in molecular quantum chemistry contained in the Q-Chem 4 program package. [Mol. Phys. 113, 184-215 (2015)]

16 Ho J., Klamt A., Coote M.L. Comment on the correct use of continuum solvent models. J. Phys. Chem. A (2010), 114(51), 1344213444.

17 Wang Y, Li H, Wang YQ, Liu Y, Foxman B. M., and, and Deng L., Asymmetric Diels-Alder Reactions of 2-Pyrones with a Bifunctional Organic Catalyst J. Am. Chem. Soc., 2007, 129 (20), 6364-6365.

18 Hiltebrandt, K.; Elies, K. D’hooge, D.R.; Blinco, J.P.; Barner-Kowollik, C. J. Am. Chem. Soc. (2016) 138, 7048-7054.

19 Menzel, J.P.; Noble, B.B.; Lauer, A.; Coote, M.L.; Blinco, J.P.; Barner-Kowollik, C. J. Am. Chem. Soc. (2017) 139, 15812-15820

20 Chen, B.; Hoffmann, R.; Cammi, R., Angew. Chem. Int. Ed. (2017) 56, $11126-11142$. 